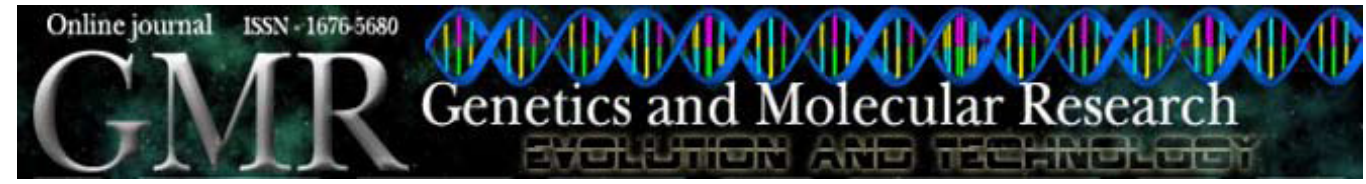

\title{
Phylogeny of major lineages of galliform birds (Aves: Galliformes) based on complete mitochondrial genomes
}

\author{
X.-Z. Kan ${ }^{1}$, J.-K. Yang ${ }^{1}$, X.-F. Li ${ }^{1}$,L. Chen ${ }^{1}$, Z.-P. Lei ${ }^{2}$, M. Wang ${ }^{1}$, \\ C.-J. Qian' ${ }^{1}$, H. Gao ${ }^{3}$ and Z.-Y. Yang ${ }^{3}$ \\ ${ }^{1}$ The Provincial Key Laboratory of the Conservation and Exploitation Research \\ of Biological Resources in Anhui, College of Life Sciences, \\ Anhui Normal University, Wuhu, China \\ ${ }^{2}$ The Administration Bureau of Wuyanling National Nature Reserve, \\ Taishun, China \\ ${ }^{3}$ State Key Laboratory of Systematic and Evolutionary Botany, \\ Institute of Botany, Chinese Academy of Sciences, Beijing, China \\ Corresponding author: X.-Z. Kan \\ E-mail: xianzhaokan@gmail.com
}

Genet. Mol. Res. 9 (3): 1625-1633 (2010)

Received May 14, 2010

Accepted June 18, 2010

Published August 17, 2010

DOI 10.4238/vol9-3gmr898

\begin{abstract}
Complete mitochondrial DNA sequences have been used successfully to estimate phylogenetic relationships among animal taxa, and for studies of population genetics and molecular evolution. We made phylogenetic analyses of 22 species of Galliformes, with two species of Anseriformes as outgroups, using maximum likelihood (ML), maximum parsimony (MP) and Bayesian inference (BI) methods based on the nucleotide dataset and the corresponding amino acid dataset of 13 concatenated protein-coding genes. The consensus phylogenetic trees supported monophyly of Galliformes, Phasianidae (nucleotide and amino acid: posterior probabilities 1.00 in BI, bootstrap value $>99 \%$ in $\mathrm{ML}$ and MP), Coturnicinae, and Gallininae (nucleotide and amino acid: posterior probabilities 1.00 in BI, bootstrap value $>85 \%$ in ML and MP), but failed to demonstrate monophyly of Pavoninae and Phasianinae. Our
\end{abstract}


results also support a sister-group relationship between megapodes and all other galliforms. We found that Arborophilinae is basal to the balance of the Phasianidae. Moreover, we suggest that the turkey should be classified in the Phasianinae of Phasianidae. Although the relationships among the various lineages of the Galliformes remain controversial, these results should be useful for further study.

Key words: Galliformes; Phylogeny; Mitochondrial genome; Maximum likelihood; Maximum parsimony; Bayesian inference

\section{INTRODUCTION}

The avian order Galliformes, comprising the landfowl or gallinaceous birds, is one of the most important groups of birds both for human society and research (Van Tuinen and Dyke, 2004). There are 281 currently recognized species of gamebirds within the order Galliformes divided among 81 genera (Sibley and Monroe, 1990; del Hoyo et al., 1994; Hockey et al., 2005). Although the order Galliformes is well defined, taxonomic relationships are less clear within the group, due to the low variability in anatomical and osteological traits (Kimball et al., 1999). Wetmore (1960) split the Galliformes into two super-families: 1) the Cracoidea, including two families, Megapodiidae and Cracidae, and 2) the Phasianoidea, including four families, Tetraonidae, Phasianidae, Numididae, and Meleagrididae. Immunological distance data on ovalbumins indicated that Opisthocomus was closer to galliforms than to cuculiforms, so Cracraft (1981) retained the family Opisthocomidae in the Galliformes. Moreover, based on cladistic interpretations of morphological and behavioral characters, Crowe (1988) concluded that cracids were sister to the balance of the phasianoids and not the megapodes, which they placed as basal within the order. A well-accepted classification of the order Galliformes recognizes seven families: Megapodiidae (mound builders, brush turkeys, and allies), Cracidae (curassows, guans, and chachalacas), Odontophoridae (New World quails), Numididae (guineafowl), Phasianidae (pheasants, partridges, Old World quails, and allies), Meleagrididae (turkeys), and Tetraonidae (grouse and allies) (del Hoyo et al., 1994). However, molecular data, albeit at this point poorly resolved, suggest instead a derived position for turkeys within Galliformes (Sibley and Ahlquist, 1990; Kimball et al., 1999). A series of studies also suggested that the New World quails and the Old World quails might form a natural group (Sibley and Ahlquist, 1990; Dimcheff et al., 2002; Dyke et al., 2003). Based on the combined evidence from phylogenetic analyses, Crowe et al. (2006) put forward a tentative revised classification of the Galliformes. In this classification, the order Galliformes recognizes five families (Megapodiidae, Cracidae, Numididae, Odontophoridae, and Phasianidae) and the family Phasianidae includes seven subfamilies (Arborophilinae, Coturnicinae, Pavoninae, Gallininae, Meleagridinae, Tetraoninae, and Phasianinae).

The mitochondrial genome of vertebrates is a small, circular molecule of $15-20 \mathrm{~kb}$, with a compact and conserved organization in most, but not all, of the studied species (Wolstenholme, 1992). It contains 37 genes: 13 protein-coding genes, 22 transfer RNA genes (tRNAs) and two ribosomal RNA genes (rRNAs), and the control region (D-loop), which controls the 
initiation of replication and transcription of animal mitochondrial DNA (mtDNA). Because their structures were relatively simple and mutation rates were higher than nuclear DNA, the mtDNA sequences were used frequently to estimate phylogenetic relationships among animal taxa, population genetics and molecular evolution. In recent years, the sequences of mtDNA have been determined at an increasing pace. Today, 109 avian mitochondrial genomes are now available in GenBank/EMBL/DDBJ. Within Galliformes, about 22 mitochondrial genomes from three major lineages of galliform birds (Megapodiidae, Numididae, and Phasianidae) have been sequenced, and the most recent record is Cabot's Tragopan, Tragopan caboti, which was determined by our research group (Kan et al., 2010).

In this study, we present phylogenetic analyses based upon the complete mitochondrial genomes of Galliformes retrieved from GenBank. We used the molecular data to examine hypotheses of the evolution of the three major lineages of Galliformes, focusing on evolutionary relationships: 1) within and among subfamilies of Phasianidae and 2) among Phasianidae, Megapodiidae, and Numididae.

\section{MATERIAL AND METHODS}

\section{Material}

Along with the complete mtDNA sequences of $T$. caboti from our research group (Kan et al., 2010), all 21 currently available complete mitochondrial sequences of Galliformes retrieved from GenBank were used in phylogenetic analysis (Table 1). Two species from Anseriformes (Anas platyrhynchos, EU009397; Branta canadensis, DQ019124) were designated as outgroups.

\begin{tabular}{|c|c|c|c|}
\hline Species & Family & Accession No. & Reference \\
\hline Arborophila rufipectus & Phasianidae & FJ194942 & He et al., 2009 \\
\hline Bambusicola thoracica & Phasianidae & EU165706 & Shen et al., 2009 \\
\hline Coturnix chinensis & Phasianidae & AB073301 & Nishibori et al., 2002 \\
\hline Coturnix japonica & Phasianidae & AP003195 & Nishibori et al., 2001 \\
\hline Francolinus pintadeanus & Phasianidae & EU165707 & Shen et al., 2009 \\
\hline Gallus gallus & Phasianidae & AP003322 & Nishibori et al., 2005 \\
\hline Gallus lafayetii & Phasianidae & AP003325 & Nishibori et al., 2005 \\
\hline Gallus sonneratii & Phasianidae & AP006741 & Nishibori et al., 2005 \\
\hline Gallus varius & Phasianidae & AP003324 & Nishibori et al., 2005 \\
\hline Lophura ignita & Phasianidae & AB164627 & Unpublished results ${ }^{\mathrm{a}}$ \\
\hline Lophura nycthemera & Phasianidae & EU417810 & Shen et al., 2009 \\
\hline Meleagris gallopavo & Phasianidae & EF153719 & Guan et al., 2009 \\
\hline Pavo muticus & Phasianidae & EU417811 & Shen et al., 2009 \\
\hline Phasianus versicolor & Phasianidae & AB164626 & Unpublished results ${ }^{\mathrm{a}}$ \\
\hline Polyplectron bicalcaratum & Phasianidae & EU417812 & Shen et al., 2009 \\
\hline Syrmaticus ellioti & Phasianidae & AB164624 & Unpublished results ${ }^{\mathrm{a}}$ \\
\hline Syrmaticus humiae & Phasianidae & AB164625 & Unpublished results $^{\mathrm{a}}$ \\
\hline Syrmaticus reevesii & Phasianidae & AB164623 & Unpublished results $^{\mathrm{a}}$ \\
\hline Syrmaticus soemmerringii & Phasianidae & AB164622 & Unpublished results $^{\mathrm{a}}$ \\
\hline Tragopan caboti & Phasianidae & GU187969 & Kan et al., 2010 \\
\hline Alectura lathami & Megapodiidae & AY346091 & Slack et al., 2007 \\
\hline Numida meleagris & Numididae & AP005595 & Nishibori et al., 2004 \\
\hline Branta canadensis & Anatidae & DQ019124 & Unpublished results $^{\mathrm{b}}$ \\
\hline Anas platyrhynchos & Anatidae & EU009397 & Unpublished results ${ }^{\mathrm{c}}$ \\
\hline
\end{tabular}

Unpublished results: a Kato S, Nishihori M and Yasue H; ${ }^{b}$ Snyder JC, Snider AR, Senecal AJ, Disantis EJ, et al.; ${ }^{\mathrm{c}} \mathrm{Tu}$ JF, Huang YH and Li N. 


\section{Phylogenetic analysis}

The nucleotide and putative amino acid regions for each of the 13 mitochondrial protein-coding genes were aligned using the default parameters of CLUSTALX version 2.0.10 (Larkin et al., 2007). To select conserved regions of the putative amino acids, each alignment was analyzed with the Gblocks $0.91 \mathrm{~b}$ program (Talavera and Castresana, 2007). We concatenated the alignments of 13 mitochondrial protein-coding genes and recovered an alignment consisting of 3795 amino acid residues. An alignment of 11,409 nucleotides was obtained using the amino acid alignment as the backbone. A substitution saturation analysis (Xia et al., 2003) was performed for subsets with the first, second and third codon positions using DAMBE 4.1.19 (Xia and Xie, 2001). According to the results, none of the substitutions from three codon positions were saturated.

The best fitting model for the nucleotide dataset was performed with jModelTest version 0.1.1 (Posada, 2008). The model of GTR $+\mathrm{I}+\mathrm{G}$ was chosen for the likelihood and Bayesian analyses. Model selection for the amino acid dataset was performed with ProtTest version 2.4 (Abascal et al., 2005), and under the Akaike information criterion, the model $\mathrm{MtREV}+\mathrm{I}+\mathrm{G}+\mathrm{F}$ fit best.

Maximum likelihood (ML) analysis of nucleotide and amino acid datasets was performed with PHYML (Guindon and Gascuel, 2003) online using the Montpellier bioinformatics platform (www.atgc-montpellier.fr/phyml) with 500 bootstrap replicates, and using GTR and MtREV models, respectively.

Maximum parsimony (MP) analysis of nucleotide and amino acid datasets was performed with PAUP version 4.0b10 (Swofford, 2002). All character states were specified as unordered and equally weighted with indels as missing data. A heuristic search was implemented with 100 random addition sequence replicates, tree bisection-reconnection branch swapping, the MULTREES option, and a maximum of 1000 trees saved per round. To evaluate relative robustness of the clades found in the most parsimonious trees, the bootstrap analysis (Felsenstein, 1985) employed 1000 replicates using the same heuristic search settings except that a maximum of 100 trees were saved per round.

Bayesian inference (BI) analysis of nucleotide and amino acid datasets was performed with MrBays 3.1.2 (Huelsenbeck and Ronquist, 2001), using GTR and MtREV models, respectively. Four Markov chains were run for 1,000,000 generations (sampling every 100 generations) to allow adequate time for convergence. After the first 2500 trees $(25 \%)$ were discarded as burn-in, the remaining 7500 sampled trees were used to estimate the $50 \%$ majority rule consensus tree and the Bayesian posterior probabilities. All MCMC runs were repeated twice to confirm consistent approximation of the posterior parameter distributions.

\section{RESULTS}

The BI, MP and ML phylogenetic trees, which are based on the nucleotide dataset and the corresponding amino acid dataset of 13 protein-coding genes, have similar topology. The unique difference of topologies from two datasets was the phylogenetic relationships among Symaticus reevesii, S. soemmerringii and (S. humiae $+S$. ellioti). The phylogenetic trees are shown in Figures 1 and 2. 


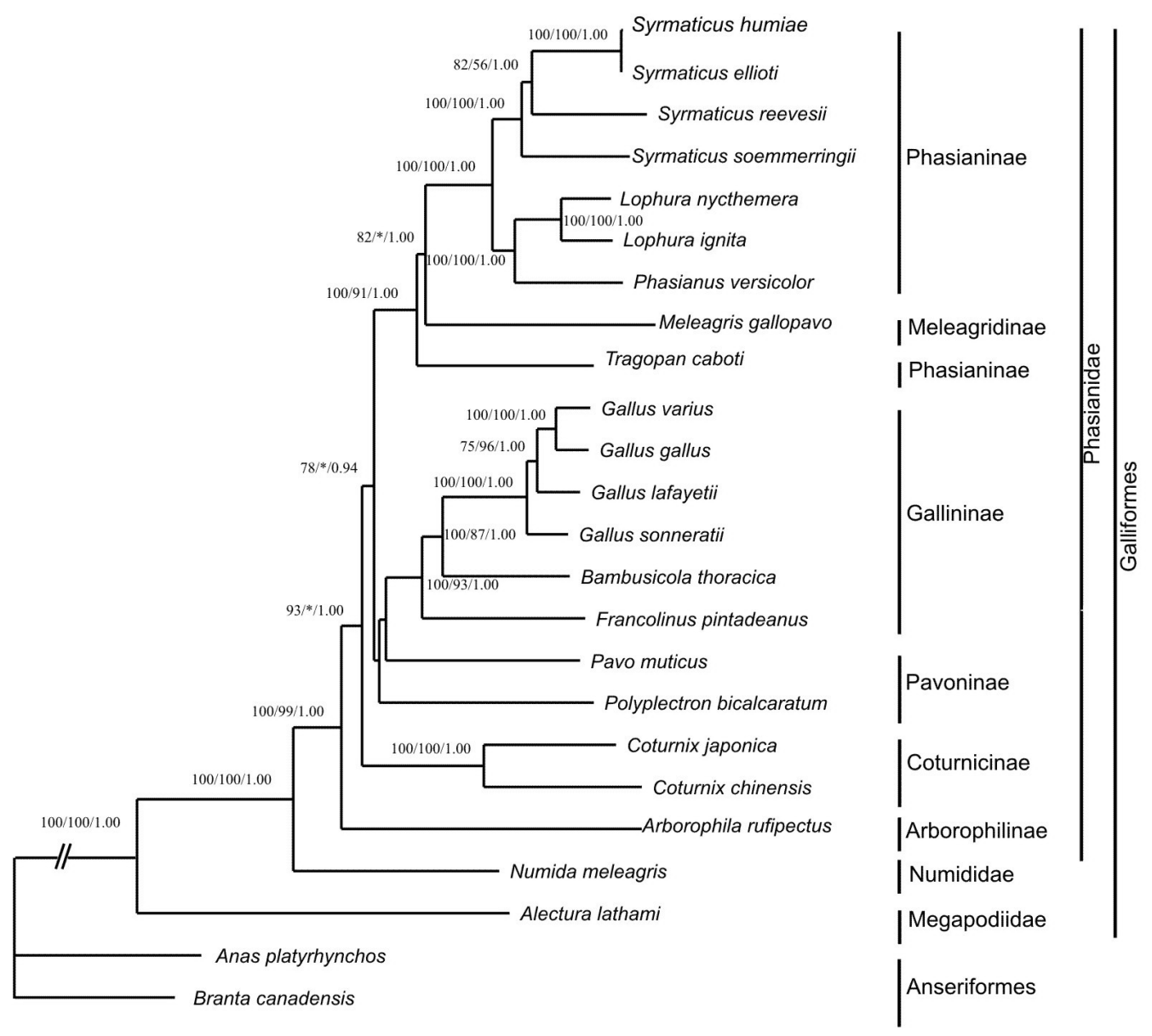

0.1

Figure 1. Phylogenetic tree of the relationships among Galliformes based on the nucleotide dataset of the 13 mitochondrial protein-coding genes. Anas platyrhynchos and Branta canadensis served as outgroups. Branch lengths and topologies came from the maximum likelihood analyses. Numbers beside the nodes specify bootstrap percentages from maximum likelihood (500 replicates) and maximum parsimony (1000 replicates), and posterior probabilities from Bayesian inference. Less than $50 \%$ bootstrap values were omitted. *Demonstrates that maximum parsimony analysis does not support this branch.

The monophyly of Galliformes and Phasianidae were well supported (nucleotide and amino acid: posterior probabilities 1.00 in BI, bootstrap value $>99 \%$ in ML and MP). Alectura lathami (Megapodiidae) is found as a sister group to all other Galliformes (nucleotide and amino acid: posterior probabilities 1.00 in BI, bootstrap value 100\% in ML and MP). Numida meleagris (Numididae) is the sister group to Phasianidae (nucleotide and amino acid: posterior probabilities 1.00 in BI, bootstrap value $100 \%$ in ML and MP). Arborophila rufipectus (Arborophilinae) was basal to the balance of Phasianidae. The monophyly of subfamilies of 

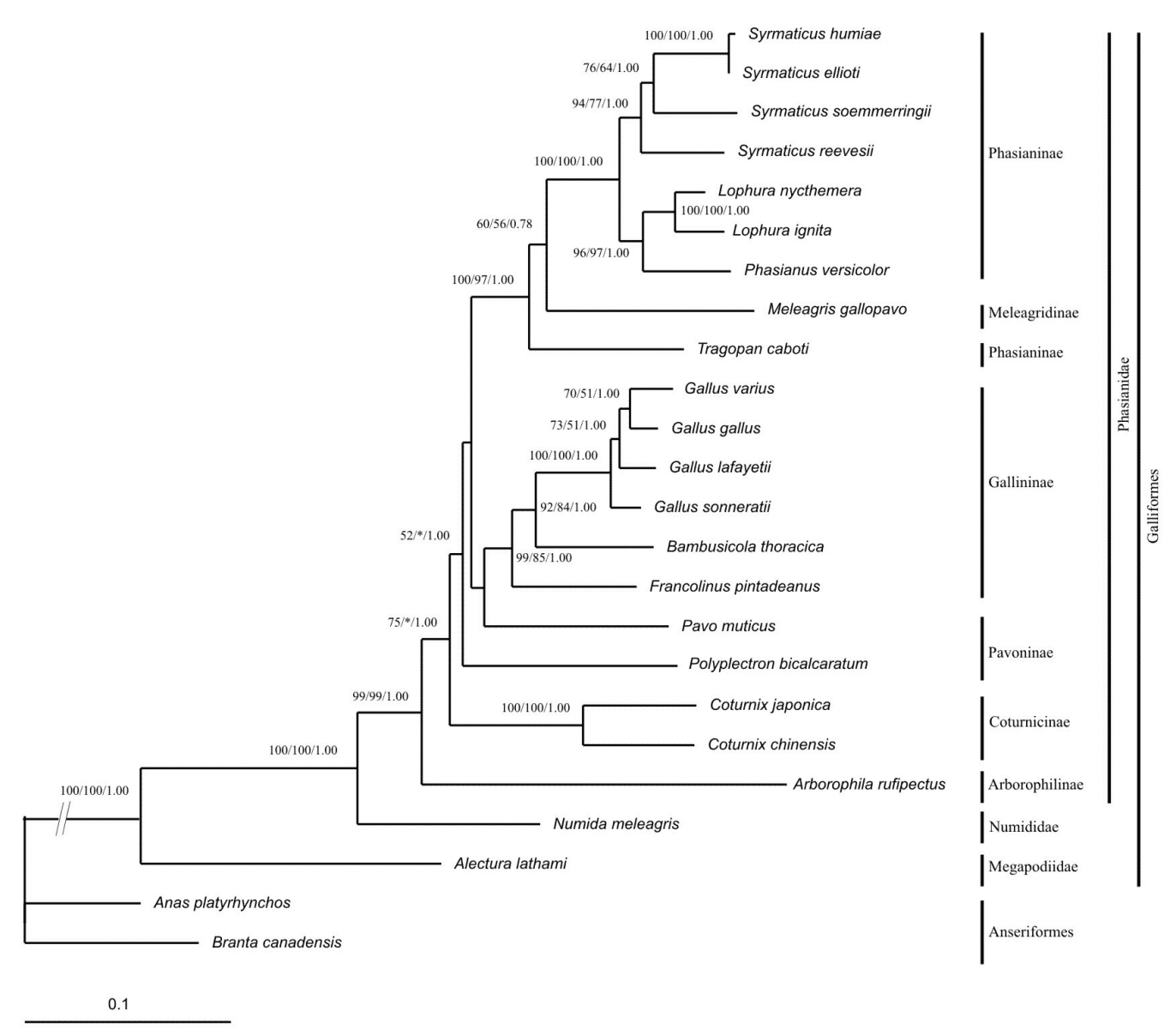

Figure 2. Phylogenetic tree of the relationships among Galliformes based on the amino acid dataset of the 13 mitochondrial protein-coding genes. Anas platyrhynchos and Branta canadensis served as outgroups. Branch lengths and topologies came from the maximum likelihood analyses. Numbers beside the nodes specify bootstrap percentages from maximum likelihood (500 replicates) and maximum parsimony (1000 replicates), and posterior probabilities from Bayesian inference. Less than $50 \%$ bootstrap values were omitted. *Demonstrates that maximum parsimony analysis does not support this branch.

Coturnicinae (Coturnix japonica + C. chinensis) and Gallininae [Francolinus pintadeanus $+($ Bambusicola thoracica + Gallus $)]$ was also well supported by nucleotide and amino acid datasets (nucleotide and amino acid: posterior probabilities 1.00 in BI, bootstrap value $>85 \%$ in ML and MP). Analyses failed to recover the monophyly of Pavoninae and Phasianinae. Meleagris gallopavo (Meleagridinae) was embedded in the Phasianinae, and T. caboti was given a basal phylogenetic position within (Phasianinae + Meleagridinae). ML and BI trees based on both datasets moderately or highly support the topologies of [Coturnicinae + (Pavoninae + Gallininae + Phasianinae + Meleagridinae $)],[($ Pavoninae + Gallininae $)+($ Phasianinae + Meleagridinae $)]$, and [Meleagridinae $+(($ Phasianus + Lophura $)+$ Syrmaticus $)]$; however, the MP trees do not support these clades. 


\section{DISCUSSION}

The Galloanserae is a monophyletic group containing 442 species and 129 genera of Anseriformes (waterfowl) and Galliformes (gamefowl) (Pereira and Baker, 2009). The close relationship of these two orders is well supported (Livezey and Zusi, 2007). So, in our phylogenetic analyses, we employed two species from Anseriformes as outgroups. Although Galliformes itself is widely regarded as a monophyletic group (Dyke et al., 2003), the relationships among the various lineages of the Galliformes are still controversial, exhibiting low levels of support or differences among studies (Kimball et al., 1999; Crowe et al., 2006). The inclusion of complete mitochondrial genomes in this study resulted in phylogeny that was partly resolved with well-supported nodes.

The first controversy is whether megapodes are the sister group of all other galliforms. The monophyly of the family Megapodiidae, which includes seven genera and 22 species, has never been seriously questioned (Birks and Edwards, 2002). However, on the phylogenetic position of the megapodes within the galliforms, several theories exist as follows: 1) Megapodes + cracids are the sister group of all other galliforms (Peters, 1934; Sibley et al., 1988); 2) Megapodes + cracids + guineafowl are the sister group of all other galliforms (Rich and van Tets, 1985); 3) Megapodes are the sister group of all other galliforms (Cracraft, 1981; Brom and Dekker, 1992; Dyke et al., 2003). Our results support a sister-group relationship between megapodes and all other galliforms.

The second controversy is whether Phasianinae is a monophyly lineage and on the phylogenetic position of the turkey (M. gallopavo) in Galliformes. In traditional classifications, the turkey was grouped in Meleagridinae of Meleagrididae, which was separated from the Phasianidae (del Hoyo et al., 1994), whereas molecular sequence analysis supported a position of Meleagridinae deeply embedded in a clade including the other Phasianidae species (Sibley and Ahlquist, 1990; Crowe et al., 2006). Our results indicated that M. gallopavo (Meleagridinae) was embedded not only in the Phasianidae, but also in the Phasianinae, and the subfamily Phasianinae was not a monophyly group. Based on mitochondrial genome, He et al. (2009) suggested that the turkey should be classified in the Phasianidae. However, taxon sampling was too limited in He et al.'s study to determine the limits of this group. Here, 20 species of Phasianidae were sampled in this study, and our results may further suggest that the turkey should be classified in the Phasianinae of Phasianidae. The relationship between the turkey and Phasianinae will require more data to resolve fully.

The third controversy is on the relationships among Syrmaticus, Lophura, and Phasianus. He et al. (2009) found that Phasianus showed a closer relationship with Lophura than Syrmaticus, whereas Kimball et al. (1999) suggested that Phasianus was closer to Syrmaticus than Lophura. Our results strongly support He et al.'s opinion (nucleotide and amino acid: posterior probabilities 1.00 in BI, bootstrap value $>96 \%$ in ML and MP).

The difficulty of resolving the branching order among the major galliform lineages suggests that these birds underwent a relatively rapid radiation (Kimball et al., 1999). Complete mitochondrial genomes have been used successfully to infer phylogenetic relationships and have been shown to recover model trees more accurately than shorter sequences (Cummings et al., 1995). Our results indicate that the evolution of the galliforms is complex and suggest that it will require additional taxa and more mitochondrial genome data. 


\section{ACKNOWLEDGMENTS}

Research supported by the National Natural Science Foundation of China (\#30870172), the State Key Laboratory of Systematic and Evolutionary Botany, China (2009), the Key Program of Natural Science Foundation of the Anhui Higher Education Institutions (\#KJ2008A13ZC), the Natural Science Foundation of Anhui Normal University (\#2008xzx14), the Key Lab. of Biotic Environment and Ecology Safety in Anhui Province, and the Program for Innovative Research Team in Anhui Normal University.

\section{REFERENCES}

Abascal F, Zardoya R and Posada D (2005). ProtTest: selection of best-fit models of protein evolution. Bioinformatics 21: 2104-2105.

Birks SM and Edwards SV (2002). A phylogeny of the megapodes (Aves: Megapodiidae) based on nuclear and mitochondrial DNA sequences. Mol. Phylogenet. Evol. 23: 408-421.

Brom TG and Dekker RWRJ (1992). Current studies on megapode phylogeny. Zool. Verhandelingen 278: 7-17.

Cracraft J (1981). Toward a phylogenetic classification of the recent birds of the world (class Aves). Auk 98: 681-714.

Crowe TM (1988). Molecules vs. morphology in systematics: a non-controversy. Trans. R. Soc. S. Afr. 46: 317-334.

Crowe TM, Bowie RCK, Bloomer P, Mandiwana TG, et al. (2006). Phylogenetics, biogeography and classification of, and character evolution in, gamebirds (Aves: Galliformes): effects of character exclusion, data partitioning and missing data. Cladistics 22: 495-532.

Cummings MP, Otto SP and Wakeley J (1995). Sampling properties of DNA sequence data in phylogenetic analysis. Mol. Biol. Evol. 12: 814-822.

del Hoyo J, Elliot A and Sargatal J (1994). Handbook of the Birds of the World. Vol. 2. Lynx Editions, Barcelona, 434-557.

Dimcheff DE, Drovetski SV and Mindell DP (2002). Phylogeny of Tetraoninae and other galliform birds using mitochondrial 12S and ND2 genes. Mol. Phylogenet. Evol. 24: 203-215.

Dyke GJ, Gulas BE and Crowe TM (2003). Suprageneric relationships of galliform birds (Aves, Galliformes): a cladistic analysis of morphological characters. Zool. J. Linn. Soc. 137: 227-244.

Felsenstein J (1985). Confidence limits on phylogenies: an approach using the bootstrap. Evolution 39: 783-791.

Guan X, Silva P, Gyenai KB, Xu J, et al. (2009). The mitochondrial genome sequence and molecular phylogeny of the turkey, Meleagris gallopavo. Anim. Genet. 40: 134-141.

Guindon S and Gascuel O (2003). A simple, fast, and accurate algorithm to estimate large phylogenies by maximum likelihood. Syst. Biol. 52: 696-704.

He L, Dai B, Zeng B, Zhang X, et al. (2009). The complete mitochondrial genome of the Sichuan Hill Partridge (Arborophila rufipectus) and a phylogenetic analysis with related species. Gene 435: 23-28.

Hockey PAR, Dean WRJ and Ryan PG (2005). Roberts-Birds of Southern Africa. 5th edn. The Trustees of the John Voclcker Bird Book Fund, Cape Town.

Huelsenbeck JP and Ronquist F (2001). MRBAYES: Bayesian inference of phylogenetic trees. Bioinformatics 17: 754-755.

Kan XZ, Li XF, Lei ZP, Wang M, et al. (2010). Complete mitochondrial genome of Cabot's tragopan, Tragopan caboti (Galliformes: Phasianidae). Genet. Mol. Res. 9: 1204-1216.

Kimball RT, Braun EL, Zwartjes PW, Crowe TM, et al. (1999). A molecular phylogeny of the pheasants and partridges suggests that these lineages are not monophyletic. Mol. Phylogenet. Evol. 11: 38-54.

Larkin MA, Blackshields G, Brown NP, Chenna R, et al. (2007). Clustal W and Clustal X version 2.0. Bioinformatics 23: 2947-2948.

Livezey BC and Zusi RL (2007). Higher-order phylogeny of modern birds (Theropoda, Aves: Neornithes) based on comparative anatomy. II. Analysis and discussion. Zool. J. Linn. Soc. 149: 1-95.

Nishibori M, Hayashi T, Tsudzuki M, Yamamoto Y, et al. (2001). Complete sequence of the Japanese quail (Coturnix japonica) mitochondrial genome and its genetic relationship with related species. Anim. Genet. 32: 380-385.

Nishibori M, Tsudzuki M, Hayashi T, Yamamoto Y, et al. (2002). Complete nucleotide sequence of the Coturnix chinensis (blue-breasted quail) mitochondrial genome and a phylogenetic analysis with related species. J. Hered. 93: 439-444.

Nishibori M, Hayashi T and Yasue H (2004). Complete nucleotide sequence of Numida meleagris (Helmeted guineafowl) mitochondrial genome. J. Poult. Sci. 41: 259-268.

Nishibori M, Shimogiri T, Hayashi T and Yasue H (2005). Molecular evidence for hybridization of species in the genus 
Gallus except for Gallus varius. Anim. Genet. 36: 367-375.

Pereira SL and Baker AJ (2009). Waterfowl and Gamefowl (Galloanserae). In: The Timetree of Life (Hedges SB and Kumar S, eds.). Oxford University Press, New York, 415-418.

Peters JL (1934). Checklist of the Birds of the World. Vol. 2. Harvard University Press, Cambridge.

Posada D (2008). jModelTest: phylogenetic model averaging. Mol. Biol. Evol. 25: 1253-1256.

Rich PV and van Tets GF (1985). Kadimakara: Extinct Vertebrates of Australia. Pioneer Design Studio, Lilydale.

Shen YY, Shi P, Sun YB and Zhang YP (2009). Relaxation of selective constraints on avian mitochondrial DNA following the degeneration of flight ability. Genome Res. 19: 1760-1765.

Sibley CG and Ahlquist J (1990). Phylogeny and Classification of the Birds. Yale University Press, New Haven.

Sibley CG and Monroe BL (1990). The Distribution and Taxonomy of the Birds of the Word. Yale University Press, New Haven.

Sibley C, Ahlquist JE and Monroe BL (1988). A classification of the living birds of the world based on DNA-DNA hybridization studies. Auk 105: 409-423.

Slack KE, Delsuc F, McLenachan PA, Arnason U, et al. (2007). Resolving the root of the avian mitogenomic tree by breaking up long branches. Mol. Phylogenet. Evol. 42: 1-13.

Swofford D (2002). PAUP*. Phylogenetic analysis using parsimony (and other methods). Version 4. Sinauer Associates, Inc., Sunderland.

Talavera G and Castresana J (2007). Improvement of phylogenies after removing divergent and ambiguously aligned blocks from protein sequence alignments. Syst. Biol. 56: 564-577.

Van Tuinen M and Dyke GJ (2004). Calibration of galliform molecular clocks using multiple fossils and genetic partitions. Mol. Phylogenet. Evol. 30: 74-86.

Wetmore A (1960). A classification for the birds of the world. Smithson. Misc. Collect. 139: 1-37.

Wolstenholme DR (1992). Animal mitochondrial DNA: structure and evolution. Int. Rev. Cytol. 141: 173-216.

Xia X and Xie Z (2001). DAMBE: software package for data analysis in molecular biology and evolution. J. Hered. 92: 371-373.

Xia X, Xie Z, Salemi M, Chen L, et al. (2003). An index of substitution saturation and its application. Mol. Phylogenet. Evol. 26: 1-7. 